\title{
DEZESSEIS ANOS DE EXISTÊNCIA
}

É com imensa satisfação que lançamos mais um número da Fênix - Revista de História e Estudos Culturais (Volume 17, Ano XVII, Número 2 - Julho / Dezembro - 2020).

No momento em que a Fênix - Revista de História e Estudos Culturais completa DEZESSEIS (16) anos de existência, temos de, mais uma vez, reiterar nossos sinceros agradecimentos e gratidão a todos(as) que se envolveram, com desprendimento e coragem, na efetividade desta revista.

Muito do que foi feito, desde o mês de dezembro de 2004, em prol da melhoria, expansão e diversificação deste periódico científico, deveu-se ao envolvimento da Secretaria Executiva, dos Conselhos Editorial e Consultivo, bem como de nosso Webmaster. Ao lado disso, devemos, com muita alegria, agradecer a todos(as) que enviaram seus artigos, pois, com essa escolha, contribuíram para que Fênix - Revista de História e Estudos Culturais pudesse se consolidar, no decorrer desses dezesseis (16) anos. Todavia, esses esforços seriam inócuos se não despertassem o interesse de nossos(as) leitores(as), a quem registramos os nossos mais sinceros agradecimentos. Em vista disso, agradecemos à

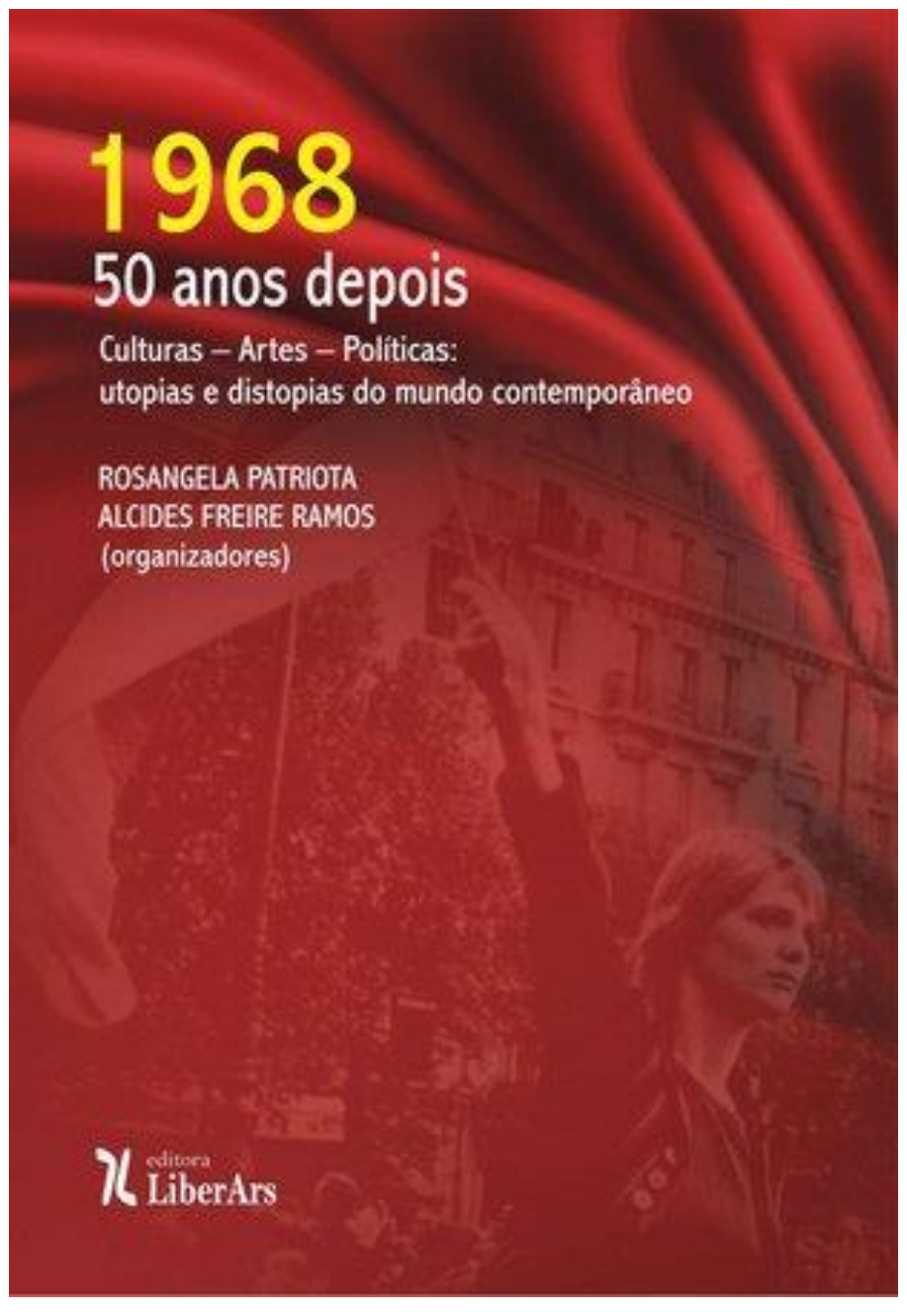
comunidade acadêmica e ao público, em geral, a acolhida de vocês a esse projeto editorial. Muito obrigado!

O site www.revistafenix.pro.br entrou no ar em dezembro de 2004 com o objetivo de trazer, ao público leitor, uma publicação que se caracterizasse pela regularidade, agilidade, universalidade e gratuidade. Essa preocupação, porém, não encerrava as expectativas depositadas em sua criação. Pelo contrário, o grande propósito era de incentivar a interlocução acadêmica e a ampla divulgação de instigantes pesquisas, com o intuito de traduzir a dinâmica e a diversidade dos diálogos interdisciplinares no âmbito da pesquisa histórica e dos Estudos Culturais. 
Os anos se passaram e, nos dias de hoje, vivemos uma situação completamente modificada. Praticamente todos os periódicos acadêmicos estão disponíveis online, e o acesso à produção científica democratizou-se. Antes, revistas nacionais e internacionais impressas, que só eram obtidas por assinatura, permuta e/ou em congressos de áreas específicas, passaram a ter seus conteúdos disponibilizados para leitura e para downloads instantaneamente.

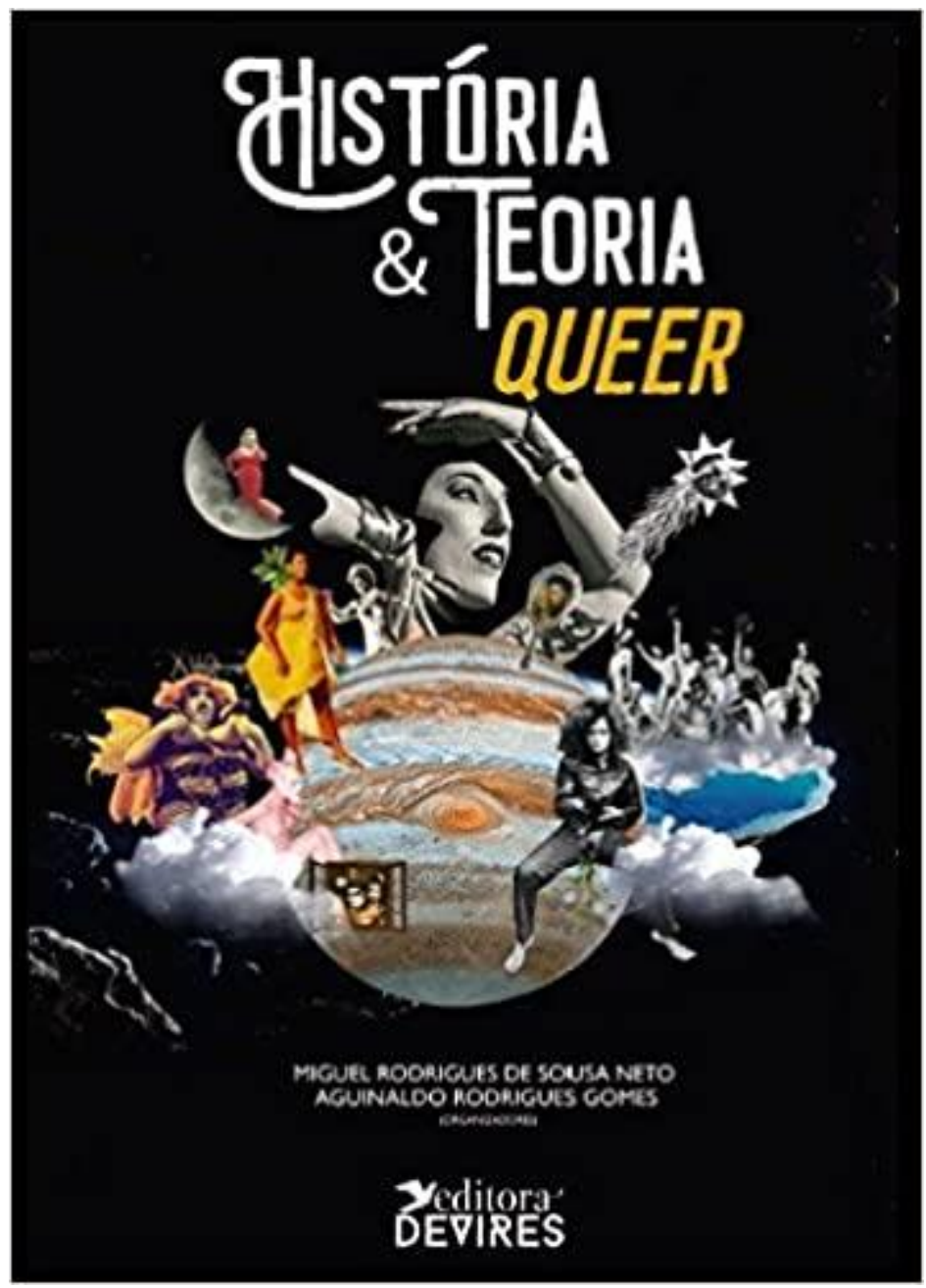

Nesse ambiente, mesmo com essa diversidade, a Fênix - Revista de História e Estudos Culturais não só se manteve ativa e com regularidade como também se consolidou pela sólida parceria estabelecida entre editores, membros de conselhos editorial e consultivo, autores e leitores e, com isso, deu passos decisivos para 0 seu amadurecimento e aceitação no meio acadêmico. Como comprovação disso, merece destaque: 0 aumento considerável da remessa de artigos, a predominância da colaboração de doutores e o recebimento de artigos internacionais. Acrescentese como indicador importante para a avaliação das atividades desenvolvidas, nesses últimos anos, o número de visitas ao site www.revistafenix.pro.br e de downloads dos arquivos. Em outros termos: até o momento, Fênix - Revista de História e Estudos Culturais recebeu a prestigiosa atenção de mais de SEIS MILHÕES (6.000.000) DE LEITORES, assim distribuídos: $70 \%$ dos acessos originam-se do Brasil, e os $30 \%$ restantes são internacionais (Portugal, EUA, México, França, Itália, Espanha, Alemanha, Suécia, Inglaterra, Japão, China, entre outros).

Nesse processo de consolidação, Fênix - Revista de História e Estudos Culturais, desde o início de 2013, por decisão de seus editores, passou a lançar seus números de seis em seis meses, sem perder a regularidade. Essa mudança, longe de apontar para um estreitamento do espaço utilizado para a divulgação de artigos e resenhas, tem permitido a otimização dos recursos humanos e materiais disponíveis para o cumprimento de todas as etapas de trabalho envolvidas na edição de uma revista científica. 
Os resultados positivos obtidos com esse projeto, considerando também a atual edição, materializam-se na publicação de CENTO E DEZESSEIS (116) RESENHAS e SEISCENTOS E NOVENTA E CINCO (695) ARTIGOS, oriundos de todas as regiões do Brasil e também de outros países. Outrossim, desde o seu surgimento, Fênix - Revista de História e Estudos Culturais tem obtido boa repercussão, que pode ser quantificada pelas citações em Teses, Dissertações, Artigos e outros resultados de produção científica. Com efeito, não é demais lembrar: essa quantificação pode ser fácil e rapidamente verificada por meio do GOOGLE SCHOLAR. Nesse sentido, do ponto de vista qualitativo, podemos dizer com tranquilidade: o impacto do periódico Fênix não se restringe

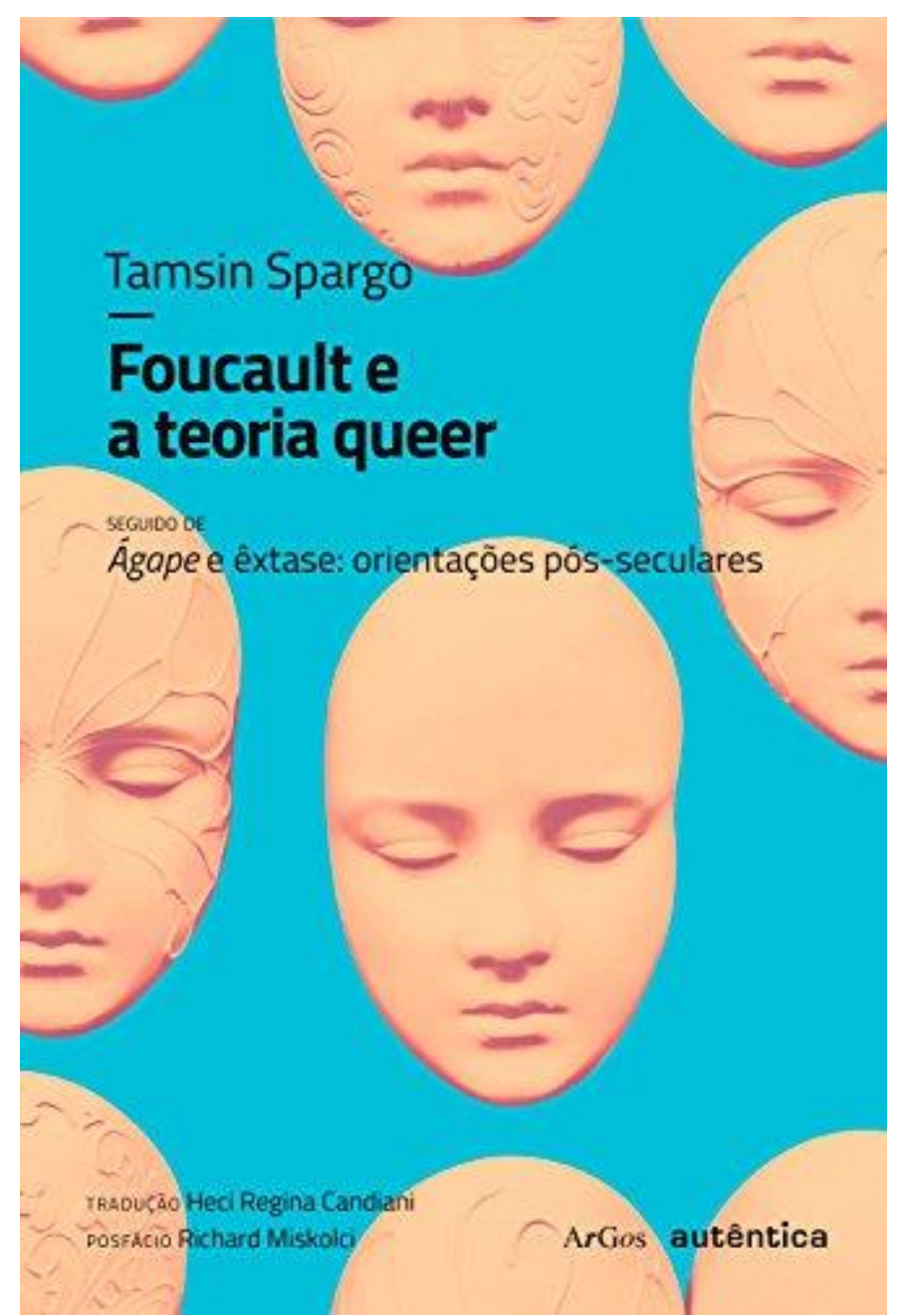

à area de História. Pelo contrário! Nas áreas de Artes, Comunicação, Letras, Sociologia, Antropologia, Turismo, Educação, entre outras, constatamos amplo uso dos artigos aqui publicados, 0 que também pode ser verificado por meio do GOOGLE SCHOLAR. Nesse sentido, é importante salientar a verificabilidade proporcionada pelo GOOGLE SCHOLAR, porque é muito comum ler (ou ouvir) reclamações infundadas quanto à dificuldade de medir 0 impacto de uma publicação eletrônica. Se o impacto dos periódicos científicos brasileiros (de um modo geral) ainda é muito baixo, isso se deve ao fato de que estamos em meio a um profundo processo de mudança, que, para muitos pesquisadores, ainda é assustador. Mas, a pouco e pouco, tanto as revistas on-line, quanto os livros eletrônicos passam a ser utilizados de maneira mais produtiva, ao lado das tradicionais publicações impressas em papel.

Ademais, ainda no que se refere ao impacto positivo obtido por este periódico, devemos lembrar: Fênix - Revista de História e Estudos Culturais acolheu VINTE E CINCO (25) DOSSIÊS, a saber: (1) Chico Buarque \& Vianinha: arte e política no Brasil Contemporâneo (organizado pela Editoria), (2) História Oral (organização de Paulo Roberto de Almeida), (3) Homenagem a Jorge Andrade - 50 anos d'A Moratória: Encruzilhadas da Literatura e da História (organização de Diógenes Maciel), (4) Cinema-História (organização de Sheila Schvarzman), (5) Teoria da História (organização de Pedro Spinola Pereira Caldas), (6) História 
e Visualidades (organização de Alcides Freire Ramos), (7) Teorias do Espetáculo e da Recepção (organização de Robson Camargo), (8) Mundo Romano (organização de Ana Teresa Marques Gonçalves), (9) Estudos Literários (organizado pela Editoria), (10) História da Ciência (organização de Antonio Augusto Passos Videira), (11) História Cultural \& Multidisciplinaridade (organizado por Sandra Pesavento, Mônica Pimenta Velloso e Antonio Herculano), (12) Sandra Jatahy Pesavento: a Historiadora e suas Interlocuções (organizado por Nádia Maria Weber Santos, Maria Luiza Martini e Miriam de Souza Rossini), (13) Jogos Teatrais no Brasil: 30 Anos (organizado por Ingrid Dormien Koudela e Robson Corrêa de Camargo), (14) O Tapete Voador Teorias do Espetáculo e da Recepção (organizado por Marcus Mota e Robson Corrêa de Camargo), (15) Tempo e História (organizado por André Fabiano Voigt), (16) Histórias Visuais: Experiências de Pesquisa entre História e Arte (organizado por Maria Elizia Borges e Heloisa Selma Fernandes Capel), (17) História e Saúde (organizado por Iranilson Buriti de Oliveira), (18) Encontros entre Brasil e Itália: Intercâmbios Acadêmicos [organizado por Rodrigo de Freitas Costa e Fulvia Zega (Università degli Studi di Genova)], (19) História e Literatura abordagens e diálogos (organizado por Euclides Antunes de Medeiros e Olivia Macedo Miranda Cormineiro), (20) Dossiê Cartas (Organizado por Francisco Alcides do Nascimento e Frederico Osanam Amorim Lima), (21) Escola sem Partido e formação humana (organizado por Nivaldo Alexandre de Freitas e Merilin Baldan), (22) História e Humor (organizado por João Pedro Rosa Ferreira, Leandro Antônio de Almeida e Thaís Leão Vieira), (23) História, Literatura e Religião (organizado por Artur Cesar Isaia), (24) Práticas e Processos Socioculturais na Amazônia (organizado por Antonio Sardinha, Marcos Vinícius de Freitas Reis e

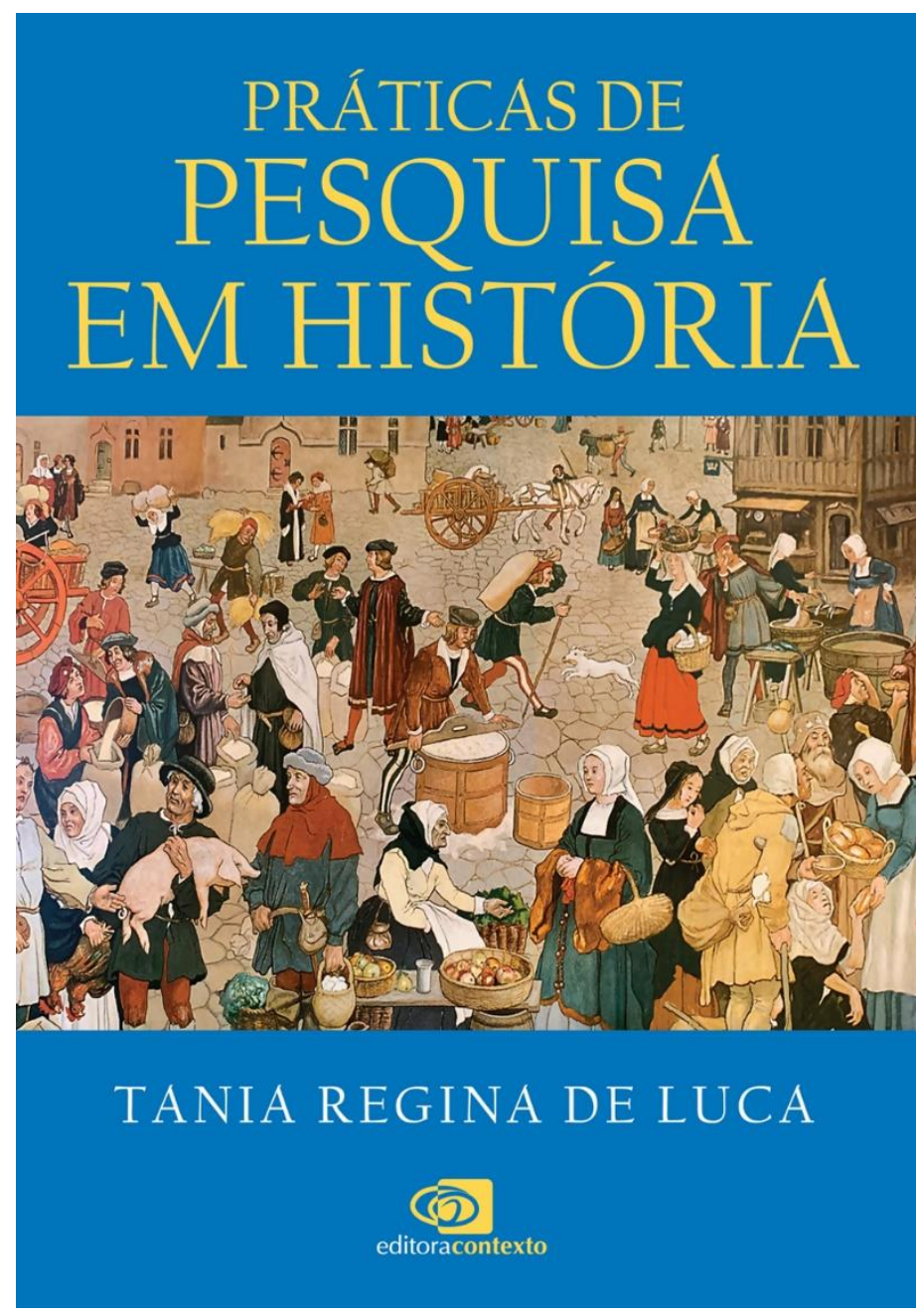
Yuji Gushiken) e (25) Os destinos das democracias nas imagens (organizado por Robson Pereira da Silva, Marcos Antonio de Menezes e Miguel Rodrigues de Sousa Netto).

Assim, em continuidade a essa trajetória exitosa, neste número temos a enorme satisfação em publicar TRINTA E SEIS (36) ARTIGOS assim distribuídos: 
DEZENOVE (19) no DOSSIÊ "Os destinos das democracias nas imagens" e DEZESSETE (17) na SEÇÃO LIVRE, que sem dúvida estimularão debates e novas reflexões.

No dossiê, que temos a honra de publicar neste número, os leitores encontrarão estímulos para refletir a respeito das imagens e suas relações com a democracia nos artigos de Emmanuel Alloa, Michel Maffesoli, Petar Bojanić, Miloš Ćipranić, Alexandre Fernandes Correa, Zélia Lopes da Silva, Jacqueline Siqueira Vigário/Anna Paula Teixeira Daher, Daniel Ivori de Matos, João Paulo Rodrigues, Edvaldo Correa Sotana, André Carvalho, Maria João Cantinho, Aguinaldo Rodrigues Gomes/Flávio Vilas-Bôas Trovão, Rafael Morato Zanatto, Sergio Pujol, Marcos Antonio de Menezes, Alcilene Cavalcante, Carmem Lúcia Sussel Mariano e Robson Pereira da Silva/Miguel Rodrigues de Sousa Netto.

Na seção livre, os artigos são múltiplos, porém sempre em interlocução com as temáticas que dão identidade ao periódico Fênix - Revista de História e Estudos Culturais. Mais uma vez, agradecemos pelos artigos enviados: Luciano Everton Costa Teles, Julierme Morais, Alcides Freire Ramos, Silvane Inês Heck/Claudia Schemes, Márcia Maria de Medeiros/Tânia Regina Zimmermann, Antonio de Pádua Bosi, Pedro Vilarinho Castelo Branco, Leonardo Q. B. Freire dos Santos, Daiane Lima dos Santos, Yago Quiñones Triana, Ketno Lucas Santiago/Francisco Pereira Smith Júnior, Anna Carolina de Abreu Coelho, Leno Francisco Danner/Julie Dorrico/Fernando Danner, Wilson Rogério dos Santos/Ana Roseli Paes dos Santos/Dinomar Rosa Araújo, Danilo Ávila, Neusa Pivotto Rodrigues/Odete Burgeile e Roselia Cristina de Oliveira.

Por fim, mas não menos importante, a seção reservada às RESENHAS presenteia o leitor com QUATRO (04) sugestões bibliográficas. De fato, merecem ser vistas, mais de perto, as avaliações críticas de Antonio Ricardo Calori de Lion, Gabriel Marques Fernandes, Felipe Biguinatti Carias e Natanael de Freitas Silva.

Mais uma vez, agradecemos pelas resenhas e artigos enviados e, antecipadamente, pelo apoio na divulgação deste periódico.

Boa leitura a todos!

Alcides Freire Ramos, Rosangela Patriota e Rodrigo de Freitas Costa Editores da Fênix - Revista de História e Estudos Culturais 